\title{
MÔ HÌNH HYDIST VÀ PHƯƠNG PHÁP XỦ LÝ NỒNG Độ PHÙ SA TẠI BIÊN LỎNG ĐỐI VỚI BÀI TOÁN HAI CHIỀU
}

\author{
Nguyễn Thị Bảy ${ }^{1}$, Trần Thị Kim² ${ }^{2}$ Huỳnh Công Hoài ${ }^{1}$, Phạm Anh Tài', \\ Nguyễn Đàm Quốc Huy ${ }^{2}$, Nguyễn Kỳ Phùng ${ }^{3}$
}

Tóm tắt: Bài báo trình bày một phưong pháp xử lý nồng độ phù sa trên biên lỏng khi dòng chảy tù miền tính chảy ra biên trong mô hình dòng chảy hai chiều kết hợp đồng nhất, xen kẽ giữa tính toán thủy lực và chuyển tải phù sa - xủ lý bằng phuoong pháp đường đặc trung. Toàn bộ mô hình được tích hợp trong phần mềm HYDIST, và tính áp dụng cho đoạn sông Tiền, thị trấn Tân Châu, tỉnh An Giang. Kết quả đã phản ánh được tính hiệu quả của phrơng pháp, các kết quả thu đuợc về lan truyền phù sa tù thượng luu sông Tiền thị trấn Tân Châu đã được truyền ra khỏi miền tính ở hạ lưu, mà không tồn đọng lại trong miền, mặc dầu miền tính được giới hạn, nhung với phưong pháp xủ lý này, phù sa trong miền tính được trao đổi tốt với miền ngoài và chảy ra ngài miền tính, mà không nhất thiết phải kéo dài miền tính. Các kết quả cho thấy tính khả thi của việc xử lý biên bằng phuơng pháp đường đặc trung trong áp dụng tính toán lan truyền chất trong sông, đặc biệt khi đoạn tính tương đối giới hạn.

Từ khóa: Mô hình chuyển tải phù sa 2D, Xủ lý biên, Phương pháp đường đặc trung, Thủy lực.

Ban Biên tập nhận bài: 12/6/2019 Ngày phản biện xong: 24/7/2019 Ngày đăng bài: 25/08/2019

\section{Giới thiệu}

Hiện nay, hầu hết các nghiên cứu về dòng chảy kết hợp với chuyển tải chất nói chung, và phù sa, diễn biến lòng dẫn nói riêng bằng mô hình toán được phát triển theo ba hướng:

(i) Áp dụng phần mềm đã xây dựng sẵn và được thương mại hóa. Có thể kể đến bộ phần mềm MIKE, được xây dựng bởi viện DHI, Đan Mạch. Bộ phần mềm này bao gồm nhiều module, được sử dụng rất phổ biến ở Việt Nam trong nghiên cứu tính toán động lực học dòng chảy. Bên cạnh đó bộ phần mềm CCHE 2, 3D do Đại học Công Nghệ Mississippi biên soạn cũng được ứng dụng mô phỏng quá trình truyền thủy lực, chuyển động bùn cát lơ lửng, bùn cát đáy và diễn biến lòng dẫn. Ngoài ra còn nhiều bộ phần mềm khác đã được thương mại hóa, tuy nhiên giá thành khá đắt đỏ.

${ }^{1}$ Đại học Bách Khoa TP. Hồ Chí Minh

${ }^{2} Đ a$ i học Tài Nguyên Môi trường TP. HCM

${ }^{3}$ Viện Khoa học Công nghệ tính toán tp. HCM

Email:ntbay@hcmut.edu.vn,

kyphungng@gmail.com (ii) Hướng thứ hai là hướng sử dụng phần mềm mã nguồn mở, có thể được tải miễn phí từ mạng như Telemac (là bộ chương trình viết trên ngôn ngữ Fortran được biên soạn bởi tập đoàn Điện lực Pháp), tuy bộ chương trình này không cần bản quyền nhưng do chưa có phần giao diện, việc khai thác và sử dụng khá phức tạp, nên hiện nay cũng chưa được phổ biến rộng rãi, mà chỉ thông qua một số chuyên gia, tổ chức mở những khóa tập huấn phần mềm. Bộ phần mềm DELFT 2,3D được sản xuất bởi Deltares - Hà Lan có thể mô phỏng 2,3D cho dòng chảy, vận chuyển trầm tích, hình thái học,...được du nhập vào Việt Nam những năm gần đây, tuy nhiên cũng chưa được phổ biến rộng rãi.

(iii) Hướng tiếp cận thứ ba là những mô hình tính thủy lực và hình thái sông tự xây dựng trong nước, những năm gần đây có thể kể đến mô hình HydroGIS của PGS.TS. Nguyễn Hữu Nhân có tích hợp công cụ GIS, demo kết quả và giao diện khá tốt. MK4 của PGS. TS. Lê Song Giang với phần giao diện khá tốt và hiện nay vẫn đang phát triển nên vẫn chưa được phổ biến rộng rãi. Mô 
hình HYDIST do tác giả tự xây dựng từ những năm 2004, và đến nay đang dần hoàn thiện. Mô hình có thể tính được dòng chảy $2 \mathrm{D}$ tích hợp cả sóng gió, và kết hợp thuần nhất, xen kẽ với chuyển tải phù sa và diễn biến đáy. Ban đầu, trong mô hình tại biên nước chảy ra được áp dụng $\frac{\partial C}{\partial S}=0$. ( $C$ là nồng độ phù sa, $s$ là phương $x$ hoặc y). Tuy nhiên kết quả khi áp dụng điều kiện này chỉ ra rằng phù sa không được trao đổi với bên ngoài vùng tính, và chỉ thích hợp để giải những bài toán với miền tính khá lớn, để điều kiện biên không ảnh hưởng nhiều đến kết quả vùng tính. Còn đối với những vùng tính giới hạn, thì điều kiện này bộc lộ nhược điểm. Với mục tiêu phát triển tiếp mô hình HYDIST, tác giả đã phát triển một phương pháp xử lý biên bằng phương pháp đường đặc trưng.

\section{Phương pháp nghiên cứu và thu thập tài liệu}

\subsection{Giới thiệu về khu vục nghiên cúu}

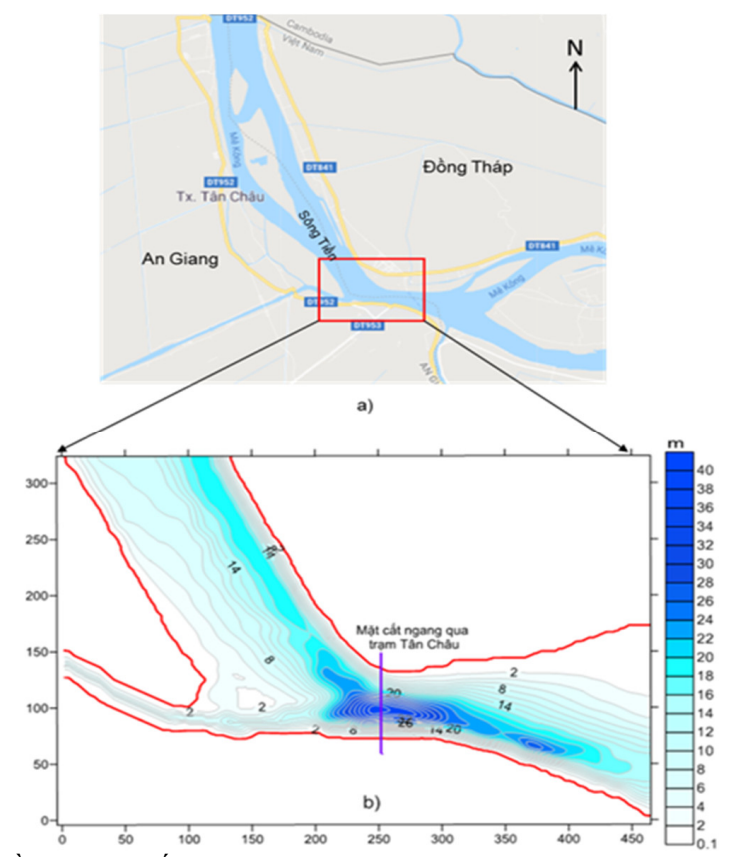

Hình 1. Vị trí đoạn sông Tiền qua thị trấn Tân Châu (a) và địa hình đoạn sông tính toán (b) với các đương đồng mức độ sâu

Đoạn sông Tiền chảy qua thị trấn Tân châu nằm ở thượng nguồn sông Tiền của Đồng bằng sông Cửu Long. Trên Hình 1 giới thiệu vị trí đoạn sông tính toán (Hình 1a) cùng độ sâu của đoạn sông đo đạc năm 1999 (Hình 1b). Trên Hình $3 b$ cũng biễu diễn mặt cắt qua trạm thủy văn Quốc gia Tân Châu. Chế độ thủy lực khu vực Tân Châu thuộc chế độ chịu ảnh hưởng của lũ từ thượng nguồn sông Mekong đổ về, dòng chảy quanh năm hầu hết theo hướng từ thượng lưu đổ về hướng biển (số thời gian dòng đổ ngược về thượng lưu rất ít, đặc biệt về mùa lũ, dòng chảy chỉ theo một hướng chảy về hạ lưu. Trên Hình 2, đường đứt nét biểu diễn lưu lượng đo đạc theo giờ tại trạm Tân Châu vào mùa lũ năm 1999 [7]. Đây cũng là cơ sở để tác giả chọn đoạn sông này để tính toán áp dụng mô hình HYDIST đã sử lý biên phù sa ở hạ lưu bằng phương pháp đường đặc trưng.

\subsection{Cơ sở lý thuyết của mô hình}

Mô hình được thiết lập dựa trên lời giải của hệ phương trình chuyển động Reynolds [10], kết hợp với phương trình chuyển tải hai chiều như sau:

Hệ phương trình Reynolds:

$$
\begin{gathered}
\frac{\partial u}{\partial t}+u \frac{\partial u}{\partial x}+v \frac{\partial u}{\partial y}=-g \frac{\partial \varsigma}{\partial x}-K u \frac{\sqrt{u^{2}+v^{2}}}{h+\varsigma}+A \nabla^{2} u \\
\frac{\partial v}{\partial t}+u \frac{\partial v}{\partial x}+v \frac{\partial v}{\partial y}=-g \frac{\partial \varsigma}{\partial y}-K v \frac{\sqrt{u^{2}+v^{2}}}{h+\varsigma}+A \nabla^{2} v \\
\frac{\partial \varsigma}{\partial t}+\frac{\partial}{\partial x}[(h+\varsigma) u]+\frac{\partial}{\partial y}[(h+\varsigma) v]=0
\end{gathered}
$$

Trong đó $\mathrm{u}, \mathrm{v}$ là thành phần vận tốc trung bình theo độ sâu của hai phương $\mathrm{x}$ và $\mathrm{y}(\mathrm{m} / \mathrm{s})$; là cao độ mực nước so với chuẩn " 0 " $(\mathrm{m})$; h là độ sâu (m).

Chuẩn " 0 " được chọn tại mặt thoáng yên lặng, trục hướng lên; $\mathrm{K}$ là hệ số ma sát đáy; $\mathrm{A}$ là hệ số nhớt rối phương ngang $\left(\mathrm{m}^{2} / \mathrm{s}\right)$; g là gia tốc trọng trường $\left(\mathrm{m} / \mathrm{s}^{2}\right)$.

Phương trình chuyển tải:

$\frac{\partial \mathrm{C}}{\partial \mathrm{t}}+\gamma\left(\mathrm{u} \frac{\partial \mathrm{C}}{\partial \mathrm{x}}+\mathrm{v} \frac{\partial \mathrm{C}}{\partial \mathrm{y}}\right)=\frac{1}{\mathrm{H}} \frac{\partial}{\partial \mathrm{x}}\left(\mathrm{HK}_{\mathrm{x}} \frac{\partial \mathrm{C}}{\partial \mathrm{x}}\right)+\frac{1}{\mathrm{H}} \frac{\partial}{\partial \mathrm{y}}\left(\mathrm{HK}_{\mathrm{y}} \frac{\partial \mathrm{C}}{\partial \mathrm{y}}\right)+\frac{\mathrm{S}}{\mathrm{H}}$

Trong đó $\mathrm{C}$ là nồng độ phù sa trung bình theo chiều sâu $\left(\mathrm{kg} / \mathrm{m}^{3}\right) ; \mathrm{K}_{\mathrm{x}}, \mathrm{K}_{\mathrm{y}}$ lần lượt là hệ số phân tán phù sa theo phương phương $\mathrm{x}$, $\mathrm{y}$ tính trung bình theo chiều sâu $\left(\mathrm{m}^{2} / \mathrm{s}\right)$; $H$ là độ sâu từ mặt thoáng xuống đáy $(\mathrm{H}=\mathrm{h}+\zeta)(\mathrm{m})$; y là hệ số phân 
bố vận tốc theo chiều sâu; $\mathrm{S}$ là hàm nguồn, mô tả sự bốc lên hay lắng xuống của hạt $\left(\mathrm{kg} /\left(\mathrm{m}^{2} . \mathrm{s}\right)\right)$.

Hàm số nguồn sẽ được tính tự động trong chương trình dựa vào những công thức thực nghiệm của Van Rijn (1993) [8-9].

$\mathrm{S}$ là hàm số xói:

$$
\mathrm{S}=\frac{\mathrm{M}}{\rho_{\mathrm{s}}} \frac{\tau_{\mathrm{b}}-\tau_{\mathrm{e}}}{\tau_{\mathrm{e}}} \quad \text { Khi } \quad \tau_{\mathrm{b}}>\tau_{\mathrm{e}}
$$

$\mathrm{S}$ là hàm số bồi:

$$
\mathrm{S}=-\omega_{\mathrm{s}} \mathrm{C}_{\mathrm{b}} \frac{\tau_{\mathrm{d}}-\tau_{\mathrm{b}}}{\tau_{\mathrm{d}}} \quad \text { Khi } \tau_{\mathrm{b}}<\tau_{\mathrm{d}}
$$

Và hàm số nguồn bằng 0 :

$$
\mathrm{S}=0 \quad \text { Khi } \quad \tau_{\mathrm{e}} \geq \tau_{\mathrm{b}} \geq \tau_{\mathrm{d}}
$$

Với $\omega_{\mathrm{s}}$ là tốc độ lắng đọng hạt $(\mathrm{m} / \mathrm{s}) ; \mathrm{M}$ là khả năng bốc hạt lên của vùng tính $\left(\mathrm{kg} / \mathrm{m}^{2} / \mathrm{s}\right)$; $\tau_{\mathrm{b}}$ là ứng suất tiếp đáy $\left(\mathrm{N} / \mathrm{m}^{2}\right)$

$$
\begin{gathered}
\tau_{\mathrm{b}}=\frac{1}{8} \rho \mathrm{f}_{\mathrm{w}} \mathrm{U}_{\mathrm{b}}^{2} \\
\mathrm{f}_{\mathrm{w}}=\frac{8 \mathrm{gn}^{2}}{\mathrm{H}^{1 / 3}}
\end{gathered}
$$

Trong đó $U_{b}$ là vận tốc đáy $(\mathrm{m} / \mathrm{s})$; $\rho$ là khối lượng riêng của nước, $\left(\mathrm{kg} / \mathrm{m}^{3}\right) ; \mathrm{C}_{\mathrm{b}}$ là nồng độ phù sa đáy $\left(\mathrm{kg} / \mathrm{m}^{3}\right) ; \mathrm{f}_{\mathrm{w}}$ là hệ số ma sát đát đáy, được tính theo Chezy (công thức (9)); n là hệ số nhám; $\tau_{\mathrm{e}}, \tau_{\mathrm{d}}$ lần lượt là ứng suất tới hạn xói và bồi $\left(\mathrm{N} / \mathrm{m}^{2}\right)$.

Các phương trình trên được giải bằng phương pháp sai phân hữu hạn, sơ đồ sai phân ẩn luân hướng ADI (Alternating Direction Implicit Method được đề xuất bởi Peaceman, Rachfor) [1], lưới của sơ đồ được trình bày trong Hình 2 .

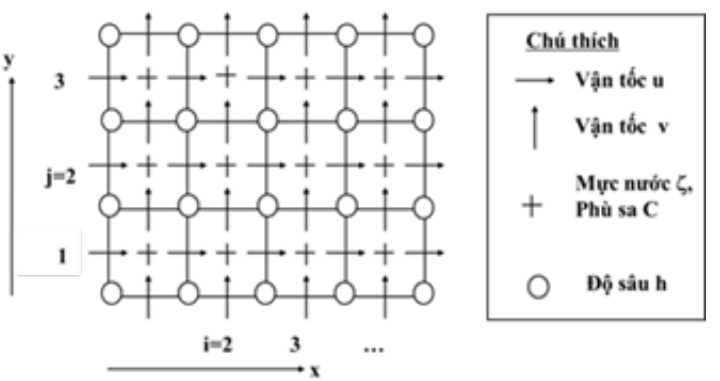

Hình 2. Lưới sai phân theo so đồ ADI

Trong đó các thành phần $\mathrm{u}, \mathrm{v}, \varsigma$ được bố trí đặc biệt, cụ thể là mực nước và nồng độ phù sa $\mathrm{C}$ được đặt ở tâm của ô lưới $(i, j)$, trong khi vận tốc $u$ được đặt ở vị trí $(i+1 / 2, j)$ và vận tốc $v$ đặt ở vị trí $(\mathrm{i}, \mathrm{j}+1 / 2)$ (với $\mathrm{i}, \mathrm{j}=1,2,3 \ldots)$. Chiều rộng của một ô lưới lần lượt là $\Delta x$ và $\Delta y$. Lưới được đánh số bằng chỉ số $\mathrm{i}$ (đối với phương $\mathrm{x}$ ) từ 1 đến $\mathrm{N}$ và $\mathrm{j}$ (đối với phương $\mathrm{y}$ ) từ 1 đến $\mathrm{M}[6]$.

\section{3. Điều kiện ban đầu và điều kiện biên của mô hình}

2.3.1. Điều kiện ban đầu

Trong mô hình, nếu bắt đầu tính từ $t_{0}=0$, thì bài toán thủy lực được gắn trạng thái tĩnh toàn miền, còn bài toán chuyển tải phù sa được gắn bằng một nồng độ nền hằng số ban đầu. Trong trường hợp bài toán được tính tiếp từ một thời điểm $\mathrm{t}=\mathrm{t} 1$ nào đó, thì điều kiện ban đầu sẽ là các trường vận tốc $\mathrm{u}, \mathrm{v}(\mathrm{x}, \mathrm{y})$ và nồng độ $\mathrm{C}(\mathrm{x}, \mathrm{y})$ tại thời điểm $\mathrm{t}_{1}$ trên toàn miền tính toán.

\subsection{2. Điều kiện biên}

Biên lỏng:

- Đối với bài toán thủy lực:

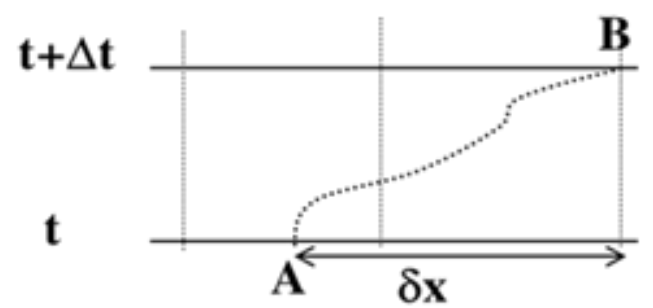

Hình 3. Quỹ đạo của hạt vật chất (di chuyển tù̀ lớp thời điểm $t$ đến $t+\Delta t$

Biên thượng nguồn dòng chảy là chuỗi dữ liệu lưu lượng đổ về miền tính theo thời gian $\mathrm{Q}(\mathrm{t})$, còn biên hạ lưu dòng chảy sẽ cho dưới dạng dao động mực nước $\varsigma(\mathrm{t})$.

- Đối với bài toán chuyển tải phù sa:

Khi dòng chảy hướng từ ngoài vào miền tính (thượng lưu), nồng độ phù sa ở biên sẽ được gán bằng nồng độ cho trước $\mathrm{C}(\mathrm{t})$, thường được nội suy từ dãy các giá trị đo đạc được hoặc tính tương quan theo thời gian.

Riêng đối với biên lỏng hạ lưu dòng chảy, khi mà dòng chảy từ miền tính hướng ra thì sử dụng điều kiện $\frac{\partial^{2} \mathrm{C}}{\partial \mathrm{S}^{2}}=0$, với $\mathrm{S}$ là phương của quỹ đạo mà hạt vật chầt được truyền đi. Khi đó, nồng độ tại biên được tính thông qua quá trình tải, quá trình khuếch tán được bỏ qua tại bước tính này. Nồng độ phù sa tại biên sẽ là nghiệm của phương trình truyền tải, được giải theo phương pháp đường đặc trưng, được trình bày kỹ trong mục 2.4.

Biên cúng đường bờ: 
Áp dụng điều kiện biên không thấm đối với bài toán thủy lực với thành phần vận tốc vuông góc bờ $u_{n}=0$ và áp dụng điều kiện phản xa toàn phần đối với bài toán chuyển tải phù sa: $\frac{\partial \mathrm{C}}{\partial \mathrm{S}}=0$.

2.4. Xử lý nồng độ phù sa tại biên lỏng bằng phương pháp đường đặc trưng

Như đã trình bày ở trên, khi dòng chảy từ miền tính chảy ra biên lỏng, phù sa tại các ô tính trước đó trong miền ảnh hưởng toàn bộ lên biên, đặc biệt là trong mùa lũ, khi mà vận tốc dòng chảy qua biên khá lớn, lúc này chuỗi dữ liệu biên $\mathrm{C}(\mathrm{t})$ cho trước tại biên trở nên không hiệu quả khi sử dụng nó làm điều kiện biên tính toán cho bài toán chuyển tải phù sa. Lúc này việc bỏ qua quá trình khuếch tán lại trở nên hữu hiệu hơn. Theo đó, người ta chấp nhận tại biên: $\frac{\partial^{2} \dot{\mathrm{C}}}{\partial \mathrm{S}^{2}}=0$

Bài toán chuyển tải được giải luân hướng theo sơ đồ ADI (đã trình bày ở trên) lần lượt theo phương $\mathrm{x}$, sau đó là phương $\mathrm{y}$. Trên mỗi phương, nồng độ trên biên sẽ được giải từ phương trình truyền tải [2]:

$$
\frac{\partial \mathrm{C}}{\partial \mathrm{t}}+\mathrm{U} \frac{\partial \mathrm{C}}{\partial(\mathrm{x}, \mathrm{y})}=\frac{\mathrm{S}}{\mathrm{H}}
$$

Hình 3 mô tả vết đi của hạt vật chất từ $\mathrm{A}$ (lớp thời điểm trước) đến vị trí trên biên lỏng $\mathrm{B}$ (lớp thời điểm sau).

Trong quá trình tải thuần túy, xem như hạt vật chất được chất lỏng mang đi với vận tốc không đổi trong khoảng thời gian $\Delta \mathrm{t}$, nồng độ tại biên $\mathrm{B}$ sẽ bằng một hàm số tính theo nồng độ tại $\mathrm{A}$ :

$$
C(B, t+\Delta t)=f(C(A, t))
$$

Để xác định nồng độ tại điểm $\mathrm{B}$ trên biên, chỉ cần đi ngược thời gian theo quỹ đạo về điểm $\mathrm{A}$, tại đây ta đã biết nồng độ (nồng độ tại $\mathrm{A}$ được biết trước hoặc được nội suy từ nồng độ tại các nút lân cận): Quá trình vừa mô tả chính là cơ sở lý thuyết của phương pháp đường đặc trưng:

Trong phương trình (10), thay: $\mathrm{U}=\frac{\mathrm{dx}}{\mathrm{dt}}$

Ta có:

$$
\frac{\partial \mathrm{C}}{\partial \mathrm{t}}+\frac{\partial \mathrm{C}}{\partial \mathrm{x}} \frac{\mathrm{dx}}{\mathrm{dt}}=\frac{\mathrm{S}}{\mathrm{H}}
$$

hay:

$$
\frac{\mathrm{dC}}{\mathrm{dt}}=\frac{\mathrm{S}}{\mathrm{H}}
$$

Lời giải của phương trình (13) với các điều kiện về nồng độ tại $\mathrm{A}$ và $\mathrm{B}$ như sau:

$$
\mathrm{C}_{\mathrm{B}}=\mathrm{C}_{\mathrm{A}}+\frac{\mathrm{S}}{\mathrm{H}} \Delta \mathrm{t}
$$

Trường hợp nếu xem như trong khoản thời gian $\mathrm{d}_{\mathrm{t}}$, sự bốc lên hay lắng đọng hạt vật chất tại lân cận biên là không đáng kể $(\mathrm{S}=0)$, ta có :

$$
\mathrm{C}_{\mathrm{B}}=\mathrm{C}_{\mathrm{A}}
$$

Trong mô hình HYDIST, điều kiện (15) được áp dụng để xác định nồng độ phù sa tại biên lỏng $\left(\mathrm{C}_{\mathrm{B}}\right)$ dựa vào nồng độ tại chân đường đặc trưng $\mathrm{C}_{\mathrm{A}}$ khi dòng chảy hướng từ miền tính ra.

Trình tự tính:

+ Bước 1: Trong khoản thời gian $\Delta \mathrm{t}$, chấp nhận vận tốc là hằng số, cụ thể trong mô hình tính bằng trung bình cộng vận tốc giữa hai lớp thời gian $n$ và $n+1$, từ đó xác định ngược lại vị trí điểm $\mathrm{A}$ tại chân đường đặc trưng.

+ Bước 2: Nội suy giá trị nồng độ tại chân đường đặc trưng (tại $\mathrm{A}$ ) theo các giá trị đã biết tại các nút.

+ Bước 3: Tính giá trị tại $\mathrm{B}$ ở lớp thời gian $\mathrm{n}+1: \mathrm{C}_{\mathrm{B}}=\mathrm{C}_{\mathrm{A}}$

Các bài toán kiểm định mô hình HYDIST về tính toán thủy lực và truyền tải phù sa đã được thực hiện và trình bày trong các bài báo đăng trong [4-5]. Sau đây chúng tôi xin giới thiệu các kết quả ứng dụng tính toán dòng chảy và chuyển tải phù sa cho đoạn sông Tiền chảy qua thị trấn Tân Châu.

\section{Các thông số áp dụng trong mô hình và hiệu chỉnh kiểm định mô hình}

\subsection{Các thông số đầu vào của mô hình}

Như đã trình bày trong mục 2.1, đoạn sông Tiền qua thị trấn Tân Châu được chọn để áp dụng tính mô hình.

Lưới tính của đoạn sông là lưới vuông góc có kích thước: 464x324 phần tử, bao gồm cả phần đất liền lẫn lòng sông, $\Delta \mathrm{x}=\Delta \mathrm{y}=10 \mathrm{~m}$; bước thời gian tính $\Delta \mathrm{t}=2 \mathrm{~s}$.

Biên lỏng trên của miền tính: dưới dạng chuỗi lưu lượng và nồng độ phù sa $\mathrm{Q}(\mathrm{t}), \mathrm{C}(\mathrm{t})$ của mùa lũ 1999 , từ đầu mùa lũ 10/5/1999 đến hết tháng 12/1999.

Biên lỏng dưới của miền tính: là dao động 
mực nước theo thời gian tương ứng, được cho từ số liệu đo đạc trạm Tân Châu dời xuống dưới trễ hơn 1 giờ.

Chương trình tính toán được viết trên ngôn ngữ VB6, để tiết kiệm thời gian tính, trong module tính toán, khi quét theo phương x hoặc y, có một chương trình con nhận dạng tự động biên bờ, để giới hạn biên đầu và biên cuối tính toán, và chỉ tính toán đến những ô trong lòng sông. Trong chương trình, để tổng quát cho trường hợp nước chảy ngược lên, vẫn nhập chuỗi phù sa $\mathrm{C}(\mathrm{t})$ cho sẵn tại biên dưới. Tuy nhiên khí tính toán trực tiếp cho đoạn sông Tiền (Tân Châu), dòng chỉ chảy theo chiều từ thượng lưu tới hạ lưu, nên chương trình tự động xử lý lại biên dưới bằng phương pháp đường đặc trưng như đã trình bày ở trên (mục 2.4), mà không sử dụng chuỗi dữ liệu phù sa biên cho sẵn.

\subsection{Hiệu chỉnh và kiểm định mô hình}

Thông số hiệu chỉnh trong mô hình là hệ số nhám. Hệ số nhám trong vùng tính được hiệu chỉnh thay đổi tỷ lệ nghịch với độ sâu lòng dẫn, và dao động trong khoảng từ 0,005 đến 0,06 tương ứng với độ sâu của lòng sông thay đổi từ $41 \mathrm{~m}$ đến $0,1 \mathrm{~m}$.

Khi tính toán, lưu lượng được trích xuất phục vụ kiểm định và hiệu chỉnh tại vị trí trạm Tân Châu để đảm bảo chế độ thủy lực.

Kết quả tính lưu lượng cho mùa lũ 1999 từ mô hình tại trạm Tân Châu so với kết quả thực đo khá chính xác (trên Hình 4, đường liền nét là kết quả tính toán, đường đứt nét là kết quả đo đạc từ ngày 5/7/1999 đến cuối tháng 12/1999).

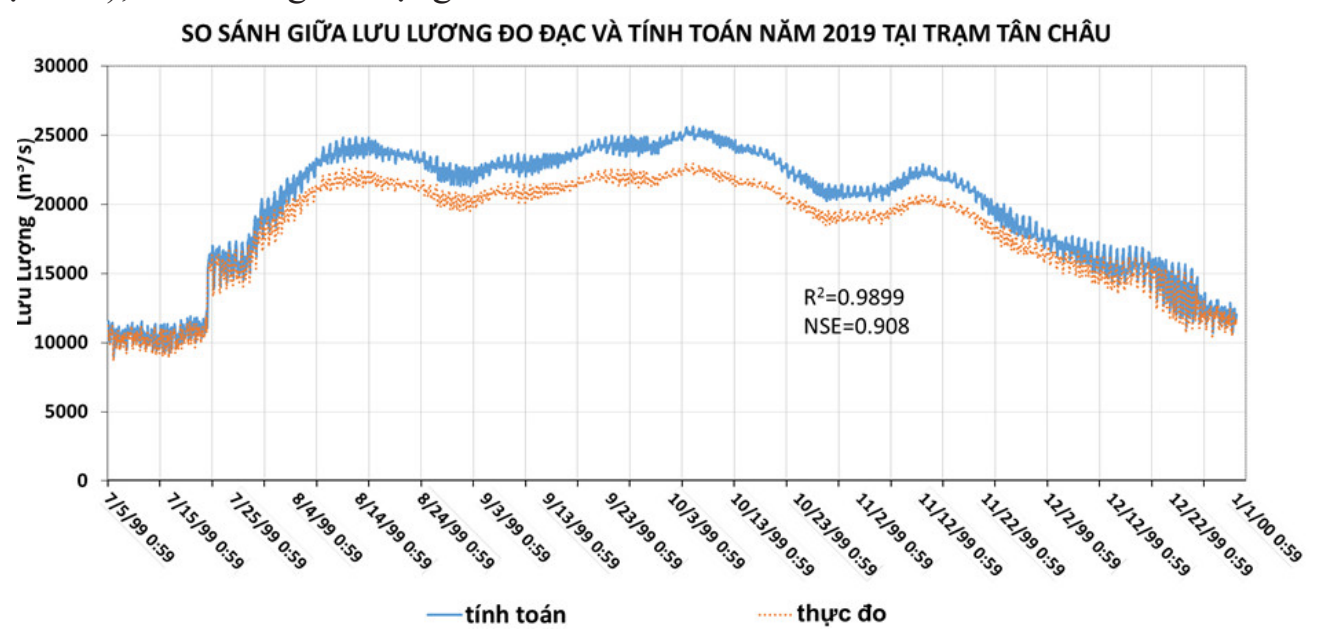

Hình 4. Lưu lượng tính tù mô hình toán và thự đo vào suòn lũ lên tù 10/5/1999 đến 24/6/1999 tại trạm Tân Châu

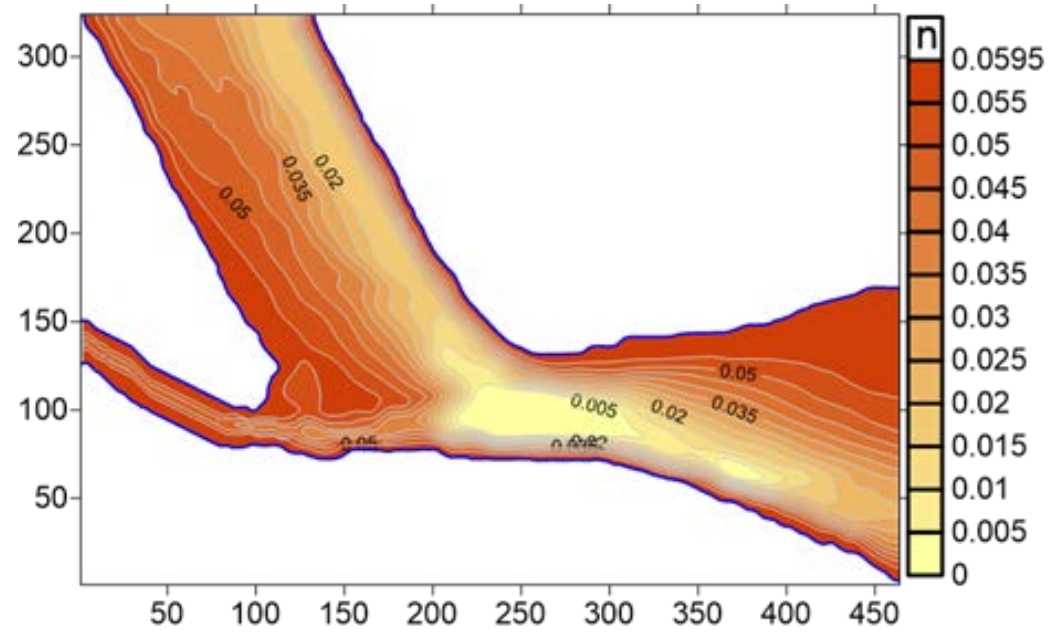

Hình 5. Kết quả phân bố hệ số nhám n trên sông Tiền-Tân Châu sau khi hiệu chỉnh 


\section{BÀI BÁO KHOA HỌC}

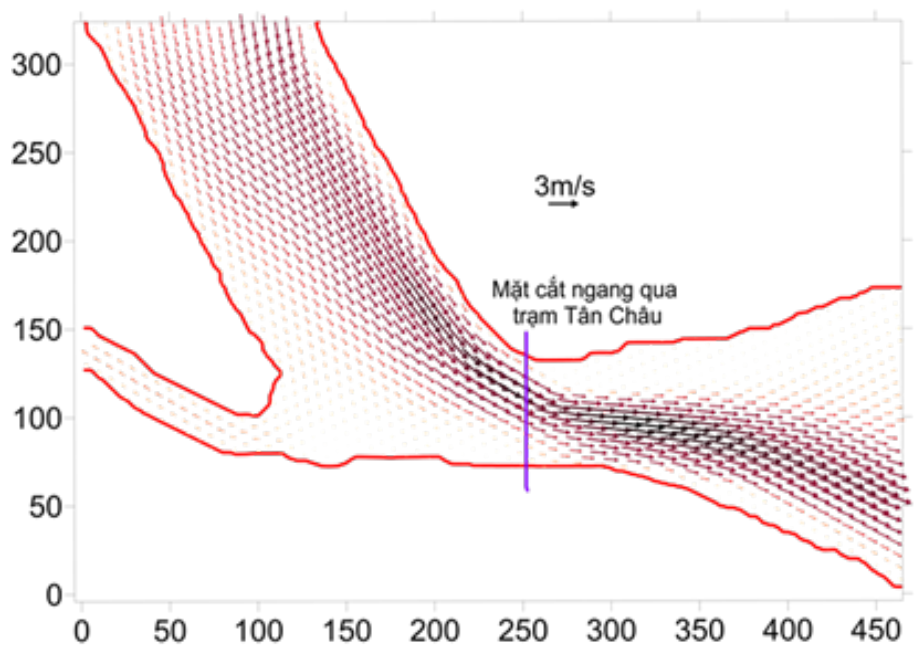

Hình 6. Kết quả tính toán truờng vận tốc trên đoạn sông Tiền (Tân Châu) lúc đỉnh lũ lúc Oh 6/10/1999
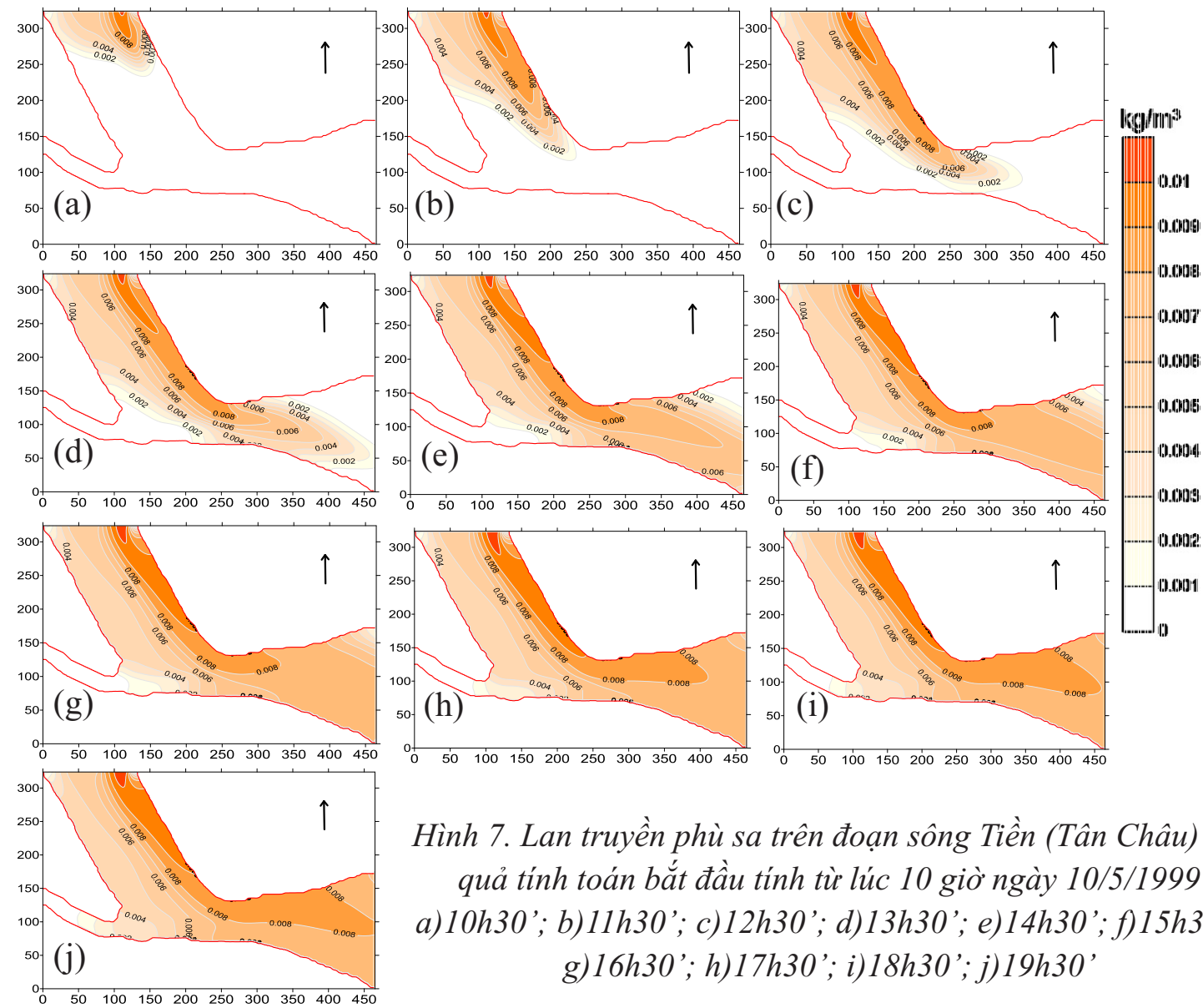

Hình 7. Lan truyền phù sa trên đoạn sông Tiền (Tân Châu) kết quả tính toán bắt đầu tính tù lúc 10 giò̀ ngày 10/5/1999 a)10h30'; b)11h30'; c) 12h30'; d)13h30'; e) $14 \mathrm{~h} 30$ '; f) 15h30'; g) $16 \mathrm{~h} 30^{\prime}$; h) $17 \mathrm{~h} 30^{\prime}$; i) $18 \mathrm{~h} 30^{\prime} ;$ j) 19h30' 
Trên Hình 5 trình bày phân bố hệ số nhám trong miền tính sau hiệu chỉnh, với màu nền thay đổi từ nhạt nhất $(\mathrm{n}=0,005)$ tại tâm của hố sâu, đến đậm nhất $(\mathrm{n}=0,06)$ tại vùng sát bờ.

\section{Thảo luận về trường vận tốc kết quả lan} truyền phù sa trong miền tính

Trường vận tốc trên đoạn sông áp dụng tính lúc đỉnh lũ (ngày 0h ngày 6/10/1999) được trình bày trong Hình 6 . Đối chiếu với độ sâu của miền tính (hình 3), vị trí ngay tại mặt cắt qua trạm thủy văn Tân Châu), vận tốc lớn nhất gần trùng với vách trên của hố sâu, đạt giá trị lên đến $3,18 \mathrm{~m} / \mathrm{s}$ (thể hiện bằng vùng véc tơ sẫm màu nhất). Hình ảnh trường vận tốc thể hiện rõ dòng chảy qua vùng khuỷu tay gấp khúc Tân Châu bám sát vách trên của hố.

Để phân tích đánh giá sự lan truyền phù sa từ thượng lưu vào miền tính và ra khỏi miền tính ở phía hạ lưu, các kết quả về lan truyền phù sa theo thời gian được xuất tương ứng với từng thời điểm sau lúc bắt đầu tính lan truyền, và vẽ thành những hình ảnh các đường đồng mức có tô màu theo độ lớn giá trị phù sa (Hình $7 \mathrm{a}-7 \mathrm{j})$ lần lượt cách nhau $1 \mathrm{~g}$ từ ngày tính đầu tiên $(10 \mathrm{~h}$ ngày 10/5/1999). Trên hình 7a thể hiện phân bố phù sa sau 30 phút đầu tiên tính toán lan truyền (lúc 10 h30'), lúc này chúng ta thấy phù sa chỉ mới bắt đầu truyền vô vùng tính và đạt giá trị lớn nhất ở đầu vào của lạch sâu (đạt tới lớn hơn 0,008 $\mathrm{kg} / \mathrm{m}^{3}$ ). Sau đó phù sa tiếp tục truyền sâu vô trong miền tính, đến $11 \mathrm{~h} 30^{\prime}$ và tiếp theo là $12 \mathrm{~h} 30^{\prime}$ (Hình 7b-7c), ta thấy phù sa đã lan truyền vô đến phân nửa của miền tính. Các kết quả và dạng các đường đồng mức phù sa trên hình $7 \mathrm{~d}$ $7 f$ chỉ ra rõ phù sa đã truyền đến tận biên dưới và di chuyển ra khỏi vùng tính sau đó (hình $7 \mathrm{~g}-7 \mathrm{j}$ ) với nồng độ phù sa đạt lên đến hơn $0,007 \mathrm{~kg} / \mathrm{m}^{3}$ tại khu vực biên hạ lưu. Nhìn vào dạng các đường đồng mức phân bố phù sa trong miền tính, cũng nhận thấy được phù sa được theo dòng chảy ra khỏi miền tính. Các kết quả này nói lên được tính ưu việt của việc xác định biên phù sa dưới bằng phương pháp đường đặc trưng như đã trình bày trong mục 2.2 , mặc dầu miền tính được giới hạn trong phạm vi khá nhỏ (so với toàn bộ hệ thống sông Tiền và sông Hậu) nhưng phù sa được truyền đi rất hợp lý từ thượng lưu về tới hạ lưu và được thoát ra khỏi miền tính, mà không tồn đọng trong miền. Nó cho thấy có sự trao đổi tốt với bên ngoài miền tính khi nước chảy ra.

\section{Kết luận}

Việc áp dụng phương pháp đường đặc trưng trong xác định nồng độ phù sa trên biên lỏng khí dòng chảy ra khỏi miền tính được các tác giả áp dụng để tính toán phù sa biên một cách hiệu quả, giúp chương trình tính toán được thực hiện dễ dàng và nhanh gọn hơn. Mô hình HYDIST đã được kiểm tra khá tốt với các bài tóan giải lý thuyết và trong phòng thí nghiệm, cũng như áp dụng tính toán thực tế trên các đoạn sông, kết quả cũng chỉ ra được tính khả thi của mô hình trong áp dụng tính toán thủy lực, chuyển tải hai chiều trên các đoạn sông khác.

Lời cảm ơn: Nghiên cứu này được tài trọ bởi đề tài mã số: NĐT.28.KR/17 trong khuôn khổ thưc nhiệm vu khoa học và công nghệ theo Nghi Định thu. Nhóm tác giả chân thành cảm ơn sụ hố trợ này.

\section{Tài liệu tham khảo}

1. Nguyễn Kỳ Phùng, Nguyễn Thị Bảy (2007), Mô hình hóa chất lượng nước mặt, NXB Đại học Quốc gia Tp. HCM.

2. Nguyễn Tất Đắc (2005), Mô hình toán cho dòng chảy và chất luợng nước trên hệ thống kênh sông, Nhà xuất bản Nông nghiệp Tp. HCM.

3. Nguyễn Thị Bảy (2004), Báo cáo tổng kết đề tài Khoa học-Công nghệ cấp Bộ: "Nghiên cưu dòng bùn cát, phù sa và sự bồi lắng của nó, Đề tài MS: B2000- 20- 82, Tp.HCM.

4. Nguyễn Thị Bảy, Mạch Quỳnh Trang (2006), Mô hình toán tính chuyển tải bùn cát kết dính 


\section{BÀI BÁO KHOA HỌC}

vùng ven biển. Phần 1: Mô hình toán, Tạp chí Phát triển Khoa học và Công nghệ. Đại học QG Tp. HCM, 9-2/2006, 53-60.

5. Nguyễn Thị Bảy, Mạch Quỳnh Trang (2006), Mô hình toán tính chuyển tải bùn cát kết dính vùng ven biển. Phần 2: Ap dung tính toán và mô phỏng dòng bùn cát vùng ven biển Cần Giò̀. Tạp chí Phát triển Khoa học và Công nghệ, 9-4/2006, 31-40.

6. Nguyen, T.B., Tran, T.T., et al. (2011), Numerical investigation on the sediment transport trend of Can Gio coastal area (Southern Vietnam). Journal of Marine Environmental Engineering, 9, 191-210.

7. Trung tâm dự báo Khí tượng Thủy văn An Giang (2000), Báo cáo nghiên cứu thủy văn phục vu xây dựng kè sông Tiền chảy qua thi trấn Tân Châu-An Giang.

8. Van Rijn, L.C., (1989), Handbook of Sediment transport by currents and waves. Vols. 1 and 2, Delft Hydraulics, Delft.

9. Van Rijn, L.C., (1993), Principles of Sediment Transport in rivers, estuaries and coastal seas, Delft Hydraulic June.

10. Vorobiev, V.N., Smimov, N.P., (2006), Hải dưong họ đại cưong: Phần 2 - Các quá trình động lực học (Phạm Văn Huấn dịch), NXB Đại học Quốc gia Hà Nội.

\section{HYDIST MODEL AND THE APPROACH OF SOLVING SEDIMENT CONCENTRATION AT OPEN BOUNDARIES Nguyen Thi Bay ${ }^{1 *}$, Tran Thi Kim², Pham Anh Tai', Nguyen Dam Quoc Huy², Huynh Cong Hoai ${ }^{1}$, Nguyen Ky Phung ${ }^{3 *}$ \\ ${ }^{1}$ Ho Chi Minh City University of Technology \\ ${ }^{2}$ Ho Chi Minh University of Natural Resources and Environment \\ ${ }^{3}$ Institute for Computational Science and Technology.}

Abstract: This paper presents a method that solves the sediment concentration at the open boundaries when the flow direction from the computational domain to open boundaries in a two-dimensional area - characteristic curves method. It combines alternatingly the hydraulic and sediment transport modules. All of these features are built and available in HYDIST model and applied for calculation in a branch of Tien River passing Tan Chau Town, An Giang Province. The results showed the effectiveness of the method, the results of spreading sediment from upstream of Tien river, Tan Chau town were transferred out of the cpmputational area. Although the study is limited, with this treatment the sediments in the area are exchanged well with the outside area and flow out into the domain, without necessarily extending the domain. The results showed the feasibility of boundary processing by the characteristic curves method in the application of sediment transport in the river, especially when the segment is relatively limited.

Keywords: 2-D Sediment transport module, processing the open boundaries, characteristic curves method, hydraulics. 